Article

\title{
Influence of Nitrogen Content and Bias Voltage on Residual Stress and the Tribological and Mechanical Properties of CrAlN Films
}

\author{
Jian-Fu Tang ${ }^{1}$, Ching-Yen Lin ${ }^{2}$, Fu-Chi Yang ${ }^{1}$ and Chi-Lung Chang ${ }^{1,2, * \mathbb{C}}$ \\ 1 Center for Plasma and Thin Film Technologies, Ming Chi University of Technology; 84 Gungjuan Rd., \\ Taishan Dist., New Taipei City 24301, Taiwan; chinglovejian@hotmail.com (J.-F.T.); \\ fcyang@mail.mcut.edu.tw (F.-C.Y.) \\ 2 Department of Materials Engineering, Ming Chi University of Technology, 84 Gungjuan Rd., Taishan Dist., \\ New Taipei City 24301, Taiwan; m07188012@mail2.mcut.edu.tw \\ * Correspondence: clchang@mail.mcut.edu.tw; Tel.: +886-2-290-89899; Fax: +886-2-290-84091
}

Received: 18 May 2020; Accepted: 4 June 2020; Published: 7 June 2020

check for updates

\begin{abstract}
This study deposited $\mathrm{CrAlN}$ coatings from $\mathrm{Al}_{50} \mathrm{Cr}_{50}$ targets using high-power impulse magnetron sputtering, with a focus on the effects of nitrogen content and substrate bias voltage on the deposition rate, microstructure, crystal orientation, residual stress, and mechanical properties of the coating. The nitrogen content was adjusted by varying the $\mathrm{N}_{2} /$ Ar flow ratio between $20 \%$ and $140 \%$. Increasing the nitrogen flow rate during deposition led to corresponding decreases in the deposition rate and film thickness. X-ray diffractometer (XRD) analysis revealed that a low $\mathrm{N}_{2}$ /Ar flow ratio $(<40 \%)$ resulted in amorphous $\mathrm{CrAlN}$, whereas a higher ratio $(>40 \%)$ resulted in an face-centered cubic (FCC) phase. Bias voltage also had considerable influence on the residual stress and grain size. A refined grain structure and high internal stress resulted in hard CrAlN coatings. Among the various parameter combinations evaluated in this study, the highest hardness (35.4 GPa) and highest elastic modulus (426 GPa) were obtained using an $\mathrm{N}_{2} / \mathrm{Ar}$ flow ratio of $100 \%$ and a bias voltage of $-120 \mathrm{~V}$.
\end{abstract}

Keywords: nitrogen content; CrAlN; residual stress; bias voltage; HiPIMS

\section{Introduction}

Transition metal nitride coatings are commonly used for the surface modification of cutting tools and mold components, due to their superior wear resistance resulting from a low coefficient of friction and high hardness [1]. Much of the research on depositing transition metal nitride films has focused on cathode arc evaporation (CAE) and DC magnetron sputtering (DCMS) [2,3]. CAE features a high deposition rate and good coating adhesion. However, high processing temperatures and the ejection of massive droplets from hot cathode spots limit its applicability to specific materials that can tolerate a high heat load and specific applications that do not depend on smooth finishes. Conventional DCMS is a low-temperature process capable of producing smooth surfaces, however, the low rate of ionization results in low film densities. Researchers have recently begun combining high-density plasma technology with magnetron sputtering, i.e., high-power impulse magnetron sputtering (HiPIMS). The films produced using this method are superior to those obtained using conventional physical vapor deposition (PVD) technologies in terms of density, hardness, and surface roughness. Shimizu et al. [4] reported that transition metal nitride coatings deposited via HiPIMS are superior to those deposited via DCMS in terms of microstructure, density, surface smoothness, and hardness $(2288 \mathrm{Hv})$. Paulitsch et al. [5] reported on the hardness of coatings obtained 
using both of these methods: $\mathrm{CrN}_{\text {HiPIMS }}\left(23 \mathrm{GPa}\right.$ ) vs. $\mathrm{CrN}_{\mathrm{DCMS}}(15 \mathrm{GPa})$ and $\mathrm{TiN}_{\mathrm{HiPIMS}}$ (35 GPa) vs. $\mathrm{TiN}_{\mathrm{DCMS}}(15 \mathrm{GPa})$.

The flexibility of HiPIMS (using individual targets) must be balanced against the cost of operating two DC supplies, however, this problem can been overcome through the use of alloy targets to create ternary films. Researchers have employed independent targets of $\mathrm{Al}$ and $\mathrm{Cr}$ to deposit $\mathrm{CrAlN}$ coatings with a fixed composition, such as $\mathrm{Cr}_{90} \mathrm{Al}_{10}$ [6], $\mathrm{Cr}_{30} \mathrm{Al}_{70}$ [7,8], $\mathrm{Cr}_{25} \mathrm{Al}_{75}$ [8], and $\mathrm{Cr}_{20} \mathrm{Al}_{80}[9,10]$. It has been reported that the hardness, oxidation resistance, and the tribological properties of $\mathrm{AlCrN}$ coatings improve with an increase in Al-content up to $70 \%-75 \%$, as long as an face-centered cubic (FCC)-structure is predominant [11]. We obtained similar results in a previous study [12]. At present, manufacturers prefer targets of $\mathrm{Al}_{70} \mathrm{Cr}_{30}$ and $\mathrm{Al}_{50} \mathrm{Cr}_{50}$. Researchers have also employed CAE or DCMS to create CrAlN films using an alloy target of $\mathrm{Cr}_{50} \mathrm{Al}_{50}$ [13]. In this study, we used HiPIMS to create CrAlN films using an alloy target of $\mathrm{Cr}_{50} \mathrm{Al}_{50}$.

The properties of CrAlN films can be altered simply by adjusting the HiPIMS processing parameters, including pressure, gas ratio, bias, and $\mathrm{CrAl}$ alloy ratio. Jiang et al. [14] reported that the microstructure and mechanical properties of AlSiN thin films are strongly related to $\mathrm{N}_{2} / \mathrm{Ar}$ flow ratios during deposition. Mahato et al. [15] reported changes in crystalline phases and grain size following the adjustment of nitrogen content. Applying a negative bias voltage to the substrate has been shown to increase the kinetic energy of the bombarding positive ions, which increases the adatom mobility (ion-bombardment-enhanced diffusion), re-sputtering, and atomic peening [16]. Biswas et al. [17] reported that higher bias voltages tend to improve the density of thin films by enhancing the intensity of ion bombardment, however, excessively high bias voltages can compromise the mechanical properties. Lomellon et al. [18] reported an increase in the hardness of $\mathrm{AlCrN}$ coatings from 33 to $50 \mathrm{GPa}$ after the bias voltage was increased from 0 to $-150 \mathrm{~V}$.

As discussed above, few studies describe the use of HiPIMS in conjunction with a $\mathrm{Cr}_{50} \mathrm{Al}_{50}$ target. In this study, we created CrAlN films using HiPIMS with a $\mathrm{Cr}_{50} \mathrm{Al}_{50}$ target, while focusing specifically on the effects of $\mathrm{N}_{2} / \mathrm{Ar}$ flow ratio and bias voltage on the resulting structure and mechanical properties.

\section{Experimental Details}

The HiPIMS system used in this work employed a simple chamber with two water-cooled 99.99\% $\mathrm{Cr}$ and $\mathrm{Cr}_{50} \mathrm{Al}_{50}$ targets. The $\mathrm{Cr}$ and $\mathrm{Cr}_{50} \mathrm{Al}_{50}$ targets $(49 \mathrm{~cm} \times 9 \mathrm{~cm})$ were connected to two pulse power supplies (Melec, SPIK 3000A, Baden-Baden, Germany and Magpuls, MP2-HC1000, Sinzheim, Germany). Deposition was performed in unipolar mode with a constant pulse on-time of $150 \mu$ s (duty cycle of $3 \%$ ) at a fixed frequency of $200 \mathrm{~Hz}$, while maintaining a target to substrate distance of $150 \mathrm{~mm}$. The calculated ion eroded area of the $\mathrm{Cr}_{50} \mathrm{Al}_{50}$ target $\left(242 \mathrm{~cm}^{2}\right)$ was used to calculate the peak power density. A Cr target was used to deposit metal and binary transition metal nitride interlayers to ensure adhesion of all coating materials. SUS304 and high-speed steel (HSS: AISI $\mathrm{M} 2,25 \mathrm{~mm}$ in diameter and $10 \mathrm{~mm}$ in thickness) substrates were cleaned in an automated cleaning line comprising a series of alkali solutions and DI water baths followed by drying in a furnace. The Si wafers underwent standard RCA cleaning. The chamber was evacuated to a base pressure of less than $6.7 \times 10^{-4} \mathrm{~Pa}$. Prior to deposition, the $\mathrm{Cr}$ and $\mathrm{Cr}_{50} \mathrm{Al}_{50}$ targets were pre-sputtered to remove surface contaminants. The working pressure was maintained at approximately $0.4 \mathrm{~Pa}$ through the injection of an $\mathrm{N}_{2} / \mathrm{Ar}$ gas mixture. An average HiPIMS power of $3 \mathrm{~kW}$ was maintained throughout the 40-min deposition process and the unheated substrate was fixed (i.e., without rotation). This research was conducted in two phases: (1) Assessing the effects of the $\mathrm{N}_{2} / \mathrm{Ar}$ gas flow ratio (expressed in percent, ranging from $20 \%-140 \%$ ) and (2) assessing the effects of substrate bias voltage ( -30 to $-150 \mathrm{~V}$ ) with the $\mathrm{N}_{2} / \mathrm{Ar}$ ratio fixed at $100 \%$. Driving waveforms were recorded using a digital oscilloscope (GW Instek GDS-2204E, New Taipei, Taiwan) with a high-voltage differential probe (GW Instek GDP-025, New Taipei, Taiwan) and probe current amplifier (GW Instek GCP-020, New Taipei, Taiwan).

The morphology of the coatings was observed using a field-emission scanning electron microscope (FE-SEM, JEOL, JSM-7000F, Tokyo, Japan). The crystalline structure of the CrAlN layers was 
characterized using a grazing incidence X-ray diffractometer (GIXRD, PANalytical, X'pert MRD, Almelo, Netherlands) with an incident angle of $0.5^{\circ}$. The power of the GIXRD instrument (Cu $\mathrm{K} \alpha$ radiation) was fixed at $45 \mathrm{kV} / 40 \mathrm{~mA}$, and measurements were obtained over diffraction angles of $20^{\circ}-90^{\circ}$. The size of crystallites in the coating was calculated using the Scherrer equation [19]: $D=0.9 \lambda /(K \cos \theta)$, where $D$ is the crystallite size perpendicular to the plane; $\lambda$ is the $X$-ray wavelength; $K$ is the full-width at half-maximum in radians; and $\theta$ is the Bragg angle. Microstrain levels were calculated using the Williamson-Hall method. The preferred orientation in the coating was determined by calculating the texture coefficient $T c(h k l)$ for each orientation using [20]:

$$
T c(h k l)=\frac{I(h k l) / I_{0}(h k l)}{\frac{1}{n} \sum_{1}^{n} I(h k l) / I_{0}(h k l)}
$$

where $I(h k l)$ is the measured diffraction line intensity, $I_{0}(h k l)$ is the standard diffraction line intensity (JCPDS database), and $n$ indicates the number of diffraction lines analyzed. Selected area electron diffraction (SAED) patterns were collected by a field-emission transmission electron microscope (JEOL, JEM-ARM200FTH, Tokyo, Japan). A field-emission electron probe microanalyzer (EPMA, JEOL, JXA-8500F, Tokyo, Japan) was used to analyze the chemical composition of the CrAlN layers. The residual stress of the coatings was evaluated using the substrate curvature method, which involved measuring the thickness of the coatings and the curvature of the Si wafer before and after deposition. Residual stress was calculated using Stoney's equation. Adhesion strength was measured via scratch tests using a Rockwell diamond stylus with the following parameters: loading speed ( $400 \mathrm{~N} / \mathrm{min})$, maximum load $(100 \mathrm{~N})$, scratch velocity $(2 \mathrm{~mm} / \mathrm{min})$, and scratch length $(5 \mathrm{~mm})$. The critical load (Lc) of the coatings was based on observations of exfoliation using an optical microscope after each scratch test. Each film was scratched four times to avoid errors. Measurements were obtained using a nanoindentation instrument (TI-900, TriboIndenter, Hysitron, Minneapolis, MN, USA) with a Berkovich $142.3^{\circ}$ diamond indenter at a maximum applied load of $6 \mathrm{mN}$. The depth of indentation was approximately $100 \mathrm{~nm}$, i.e., about on tenth the thickness of the CrAlN layer. The hardness and elastic modulus of each indent were determined using the Oliver and Pharr method [21]. The elastic modulus, E, was derived as follows:

$$
\frac{1}{E_{\mathrm{r}}}=\frac{\left(1-v^{2}\right)}{E}+\frac{\left(1-v_{\mathrm{i}}^{2}\right)}{E_{\mathrm{i}}}
$$

where $E_{\mathrm{r}}$ and $v$, respectively, indicate the reduced modulus and Poisson's ratio in the thin film, and $E_{\mathrm{i}}$ (1140 GPa) and $v_{\mathrm{i}}(0.07)$ are the parameters corresponding to the diamond indenter [22]. The quoted hardness values are the average of at least five readings. The friction coefficients of coatings grown on the HSS substrate were measured using a tribometer (CSM Instruments, Needham, MA, USA) with a ball-on-disk configuration (standard HSS ball with a diameter of $6 \mathrm{~mm}$ ) at a sliding speed of $27 \mathrm{~cm} / \mathrm{s}$ and a normal load of $1 \mathrm{~N}$ at room temperature under dry conditions. Note that the sliding rotational radius of the ball was $7 \mathrm{~mm}$.

\section{Results and Discussion}

\subsection{Effects of $\mathrm{N}_{2} / \mathrm{Ar}$ Flow Ratio on the CrAlN Layer}

Increasing the $\mathrm{N}_{2} / \mathrm{Ar}$ flow ratio (from $20 \%$ to $140 \%$ ) was shown to increase the peak current (from 352 to $608 \mathrm{~A}$ ), peak voltage (from -800 to $-640 \mathrm{~V}$ ), and peak power (from 281.6 to $389.1 \mathrm{~kW}$ ) during HiPIMS pulses. As shown in Table 1, there was also a notable increase in the peak power density (from 1.16 to $1.60 \mathrm{~kW} / \mathrm{cm}^{2}$ ), which improved the quality of the deposited film in terms of microstructure density and surface roughness [14]. Under all operating conditions, the peak power density $\left(>1 \mathrm{~kW} / \mathrm{cm}^{2}\right)$ met the requirements of HiPIMS and exceeded that of conventional DC-MS systems [23]. The increase in the target power density can be attributed to the increase in peak current 
made possible by the reactive gas $\left(\mathrm{N}_{2}\right)$ increasing secondary electron emissions from the target [24]. The peak power density of the $\mathrm{Cr}$ target is not discussed as it was used only to deposit an interlayer under a fixed $\mathrm{N}_{2} /$ Ar flow ratio.

Table 1. $\mathrm{N}_{2}$ /Ar flow ratios and corresponding effects on peak power density and concentrations of constituent elements in CrAlN coatings.

\begin{tabular}{|c|c|c|c|c|c|c|c|c|}
\hline \multirow{2}{*}{$\mathrm{N}_{2} / \operatorname{Ar}(\%)$} & \multirow{2}{*}{$\begin{array}{c}\text { Peak Power } \\
\text { Density }\left(\mathrm{kW} / \mathrm{cm}^{2}\right)\end{array}$} & \multicolumn{4}{|c|}{ Atomic Ratio (at.\%) } & \multirow{2}{*}{ Al/Cr Ratio } & \multirow{2}{*}{$\mathrm{Al} /(\mathrm{Al}+\mathrm{Cr})$ Ratio $\mathrm{x}$} & \multirow{2}{*}{ N/(Al+Cr) Ratio } \\
\hline & & Al & $\mathrm{Cr}$ & $\mathbf{N}$ & $\mathrm{O}$ & & & \\
\hline 20 & 1.16 & 37.9 & 36.1 & 25.6 & 0.40 & 1.05 & 0.51 & 0.34 \\
\hline 60 & 1.26 & 24.7 & 22.7 & 52.3 & 0.28 & 1.08 & 0.52 & 1.11 \\
\hline 80 & 1.46 & 24.6 & 22.3 & 52.9 & 0.23 & 1.09 & 0.52 & 1.12 \\
\hline 100 & 1.52 & 24.2 & 22.2 & 53.1 & 0.48 & 1.08 & 0.52 & 1.14 \\
\hline
\end{tabular}

Table 1 also lists the concentration of constituent elements in the CrAlN layers produced under various $\mathrm{N}_{2} / \mathrm{Ar}$ flow ratios. An increase in $\mathrm{N}_{2} / \mathrm{Ar}$ flow ratios was shown to reduce the atomic ratios of $\mathrm{Cr}$ and Al. Note that under a low $\mathrm{N}_{2} / \mathrm{Ar}$ flow ratio $(<60 \%)$, the atomic ratio of $\mathrm{N}$ was higher, due to the availability of $\mathrm{N}_{2}$ molecules and $\mathrm{N}^{2+}$ ions in gaseous phase, which increased the collision frequency in the plasma and in so doing lowered the sputtering yield of $\mathrm{Al}$ and $\mathrm{Cr}$ [1]. An increase in the $\mathrm{N}_{2} / \mathrm{Ar}$ flow ratio was also shown to increase the $\mathrm{Al} / \mathrm{Cr}$ ratio, due to the fact that the sputtering threshold energy of $\mathrm{Al}(13 \mathrm{eV})$ is lower than that of $\mathrm{Cr}(22 \mathrm{eV})$ [25]. Finally, the CrAlN films still contained a relatively small number of nitrogen atoms $(\mathrm{N} /(\mathrm{Al}+\mathrm{Cr})<1)$; i.e., the material properties of the $\mathrm{CrAlN}$ films were similar to those of a metal (or metal-rich nitride). Increasing the $\mathrm{N}_{2} / \mathrm{Ar}$ flow ratio to beyond $60 \%$ did not lead to a further increase in $\mathrm{N}$ content. At that point, the CrAlN films became saturated $(\mathrm{N} /(\mathrm{Al}+\mathrm{Cr})>1)$; i.e., the material properties of the CrAlN films were similar to those of a fully nitride-coated film. The $\mathrm{Al} /(\mathrm{Al}+\mathrm{Cr})$ ratio was maintained at a constant $\sim 0.5$, which prevented the formation of $\mathrm{h}-\mathrm{AlN}$ phase in the CrAlN films. Note that the oxygen content in all of the films was less than 0.5 at. $\%$.

Figure 1 presents XRD patterns of CrAlN layers deposited under various $\mathrm{N}_{2} / \mathrm{Ar}$ flow ratios. A low $\mathrm{N}_{2} /$ Ar flow ratio $(<40 \%)$ resulted in an amorphous CrAlN layer, due to the fact that the number of $\mathrm{Me}-\mathrm{N}$ bonds in the film was insufficient to form crystalline structures. Note that the crystalline structure was confirmed by selected area electron diffraction (SAED) analysis. An intermediate $\mathrm{N}_{2} / \mathrm{Ar}$ flow ratio (40\%-80\%) resulted in CrAlN layers with FCC structures showing (111), (200), and (220) diffraction peaks indicative of $\mathrm{CrN}$ phase. When the $\mathrm{N}_{2} / \mathrm{Ar}$ flow ratio exceeded $80 \%$, the observed $2 \theta$ values for (111), (200), and (220) reflections were below standard $2 \theta$ values, due to the effects of internal stress in the coatings. Changes in the preferred orientation as a function of $\mathrm{N}_{2} / \mathrm{Ar}$ flow ratio were estimated qualitatively in terms of texture coefficients. Note that when the $\mathrm{N}_{2} / \mathrm{Ar}$ flow ratio was increased from $60 \%$ to $140 \%$, the preferred orientation changed from (111) to (200). Paulitsch et al. reported the preferential growth of crystals with a (200) orientation following an increase in ion density [5]. Researchers have also reported that increases in bombardment levels gradually induce a preferential orientation change from (111) to (200) or (220) [26]. In the current study, increasing the $\mathrm{N}_{2} / \mathrm{Ar}$ flow ratio produced an increase in peak power density, which provided the bombarding species with additional energy. When the nitrogen content was increased from $60 \%$ to $140 \%$, the lattice parameter of the CrAlN layer increased from $0.4128 \mathrm{~nm}$ to $0.4187 \mathrm{~nm}$ and the microstrain increased from $3.57 \times 10^{-3}$ to $5.33 \times 10^{-3}$. When $\mathrm{Cr}$ was mixed into the $\mathrm{AlN}$, larger $\mathrm{Cr}$ atoms occupied some of the $\mathrm{Al}$ sites to form a $\mathrm{CrAlN}$ solid solution, thereby altering the lattice parameters, as follows: $\mathrm{CrN}$ $(0.41480 \mathrm{~nm})$ and AlN $(0.4045 \mathrm{~nm})[20,25]$. Table 2 summarizes the computed lattice parameters, texture coefficients, and microstrain values of the various coatings. Note that the hexagonal wurtzite structure characteristic of AlN crystals did not appear in any of the films, due to the low $\mathrm{Al} /(\mathrm{Al}+\mathrm{Cr})$ ratio; i.e., below the critical point at which AlN would form. Previous studies reported a phase transformation from an FCC to a hexagonal close packed (HCP) structure under high $\mathrm{Al}$ concentrations $(\mathrm{Al} /(\mathrm{Al}+\mathrm{Cr})$ 
ratio $>66 \%$ ) [12]. Figure 2 presents the SAED images obtained using a transmission electron microscope (TEM) from CrAlN layers formed under $\mathrm{N}_{2} /$ Ar flow ratios of $20 \%, 60 \%$, and $100 \%$. The SAED patterns clearly indicate the amorphous structure of the CrAlN layers formed under an $\mathrm{N}_{2} / \mathrm{Ar}$ flow ratio of $20 \%$. Increasing the nitrogen content beyond that point caused a structural transformation from amorphous to crystalline. Note that these results are in good agreement with our GIXRD results.

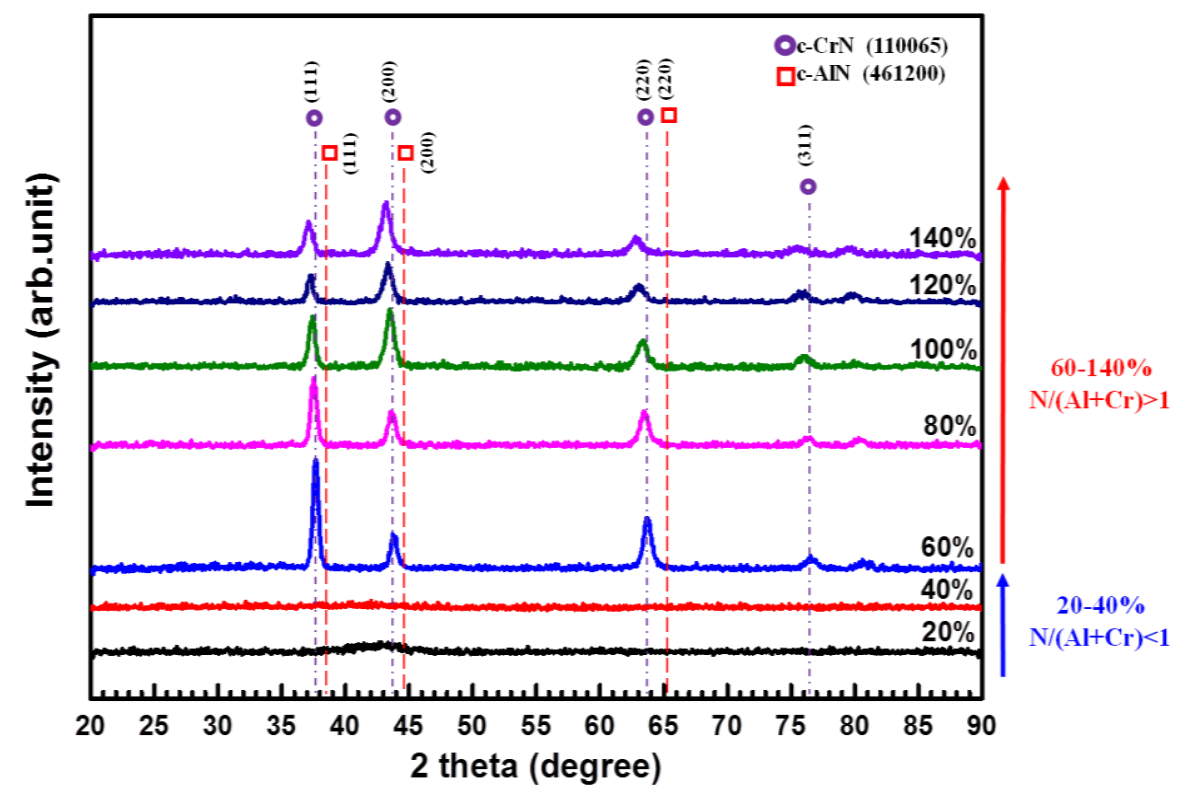

Figure 1. Grazing incidence X-ray diffractometer (GIXRD) profiles of CrAlN layers as a function of $\mathrm{N}_{2} /$ Ar flow ratio.

Table 2. Lattice parameters and texture coefficient of CrAlN layer under various $\mathrm{N}_{2} / \mathrm{Ar}$ flow ratios.

\begin{tabular}{cccccc}
\hline \multirow{2}{*}{$\mathbf{N}_{\mathbf{2}} /$ Ar (\%) } & \multirow{2}{*}{ Lattice Parameter (nm) } & Microstrain $\varepsilon$ & \multicolumn{3}{c}{ Texture Coefficient Tc } \\
\cline { 3 - 5 } & & & $\mathbf{( 1 1 1 )}$ & $\mathbf{( 2 0 0 )}$ & $\mathbf{( 2 2 0 )}$ \\
\hline 60 & 0.4128 & $3.57 \times 10^{-3}$ & 1.39 & 0.37 & 1.23 \\
80 & 0.4143 & $4.07 \times 10^{-3}$ & 1.26 & 0.52 & 1.22 \\
100 & 0.4156 & $5.01 \times 10^{-3}$ & 1.01 & 0.96 & 1.03 \\
120 & 0.4170 & $5.33 \times 10^{-3}$ & 0.87 & 1.03 & 1.09 \\
140 & 0.4187 & $4.80 \times 10^{-3}$ & 0.98 & 1.12 & 0.89 \\
\hline
\end{tabular}
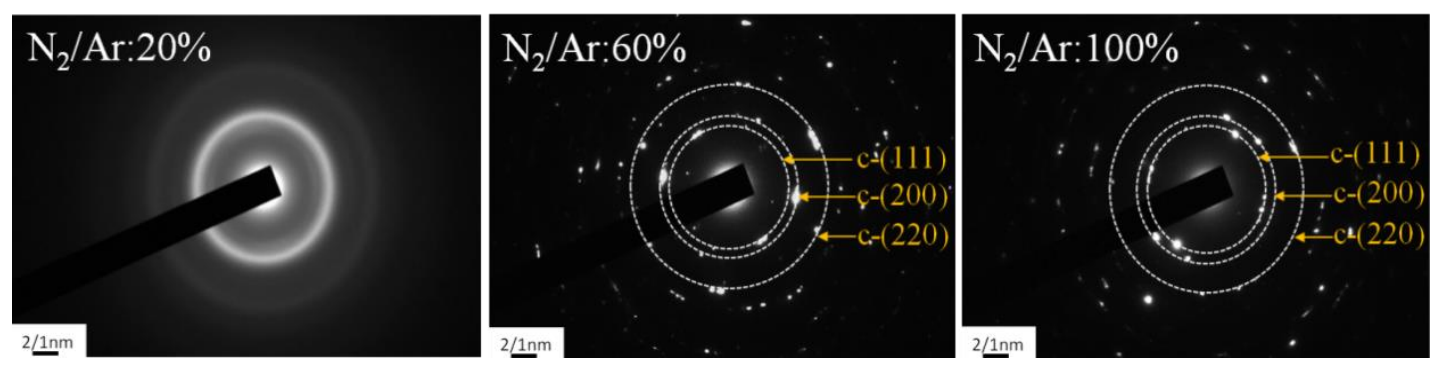

Figure 2. Selected area electron diffraction (SAED) patterns of CrAlN layers formed under $\mathrm{N}_{2} / \mathrm{Ar}$ flow ratios of $20 \%, 60 \%$, and $100 \%$.

Figure 3 presents cross-sectional SEM images of coatings deposited under various $\mathrm{N}_{2} / \mathrm{Ar}$ flow ratios. The red-dotted line demarcates the CrAlN top layer. Under an $\mathrm{N}_{2} / \mathrm{Ar}$ flow ratio of $<40 \%$, no columnar-type structures were observed in the CrAlN. Under an $\mathrm{N}_{2} / \mathrm{Ar}$ flow ratio $>40 \%$, all of the $\mathrm{CrAlN}$ layers exhibited columnar-type structures. When the nitrogen content was increased (from $20 \%$ to $140 \%$ ), the thickness of the CrAlN layer decreased from 2.86 to $0.97 \mu \mathrm{m}$ and the deposition rate 
decreased from 71.5 to $24.3 \mathrm{~nm} / \mathrm{min}$. This was partly due to the fact that the sputtering rate of nitrided compounds is lower than that of metals [27]. Furthermore, the Me-N layers produced secondary electron emission yields higher than the metal targets, which further lower the sputtering yield of the targets [28].
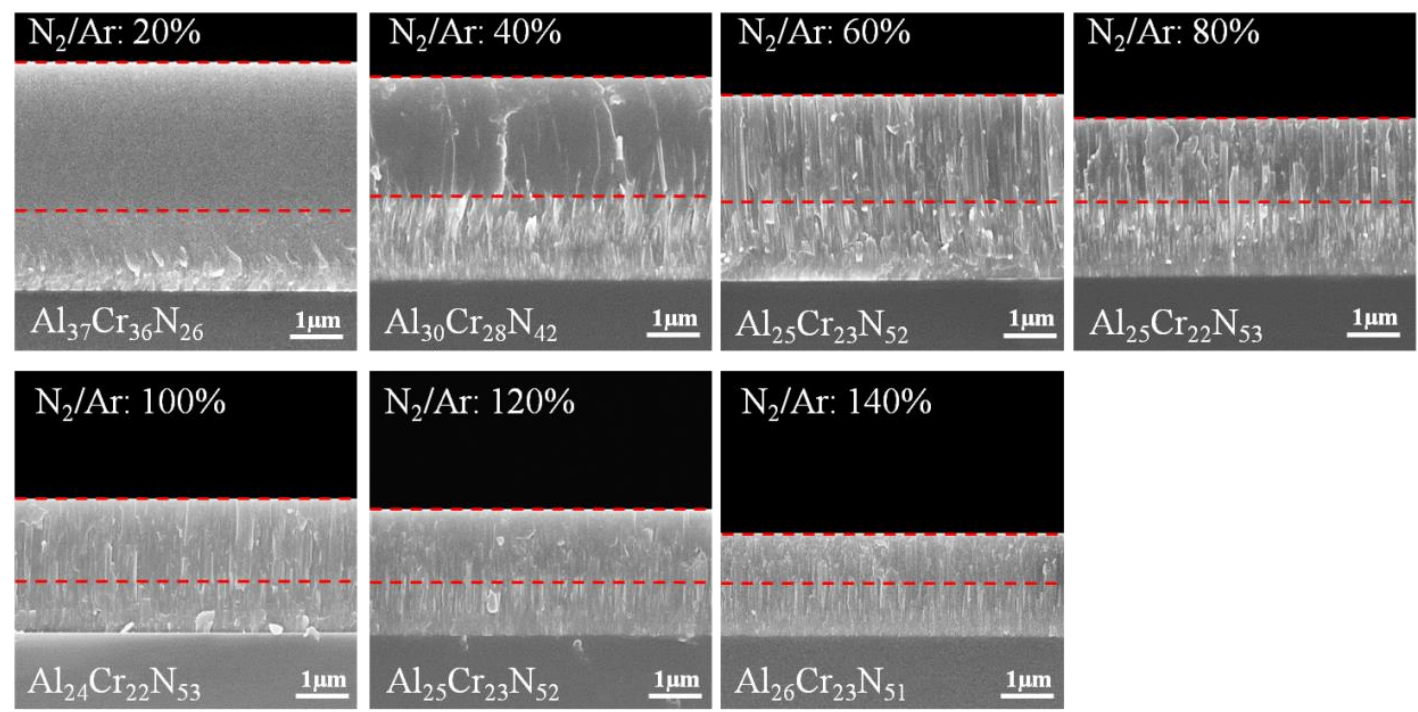

Figure 3. Cross-sectional scanning electron microscope (SEM) images of coatings deposited under various $\mathrm{N}_{2}$ /Ar flow ratios.

Figure 4 presents the hardness and Young's modulus of CrAlN layers formed under various $\mathrm{N}_{2} / \mathrm{Ar}$ flow ratios. The highest hardness value $(29.3 \pm 0.6 \mathrm{GPa})$ and Young's modulus (406.1 $\pm 15 \mathrm{GPa})$ were obtained when the $\mathrm{N}_{2}$ /Ar flow ratio was $100 \%$. The hardness values of all of the samples presented characteristic slopes in the linear fitting plot. There was a strong positive correlation between $\mathrm{N}_{2} / \mathrm{Ar}$ flow ratios (from $20 \%$ to $80 \%$ ) with hardness values (from $11.5 \pm 0.5$ to $21.7 \pm 1.3 \mathrm{GPa}$ ) and with Young's modulus (from $207.9 \pm 7$ to $383.7 \pm 14 \mathrm{GPa}$ ), due to the replacement of a large number of $\mathrm{Me}-\mathrm{Me}$ bonds with $\mathrm{Me}-\mathrm{N}$ bonds in the CrAlN film. At $\mathrm{N}_{2} /$ Ar flow ratios exceeding 100\%, the samples became saturated with nitrogen, such that the composition, crystal structure, and corresponding hardness and Young's modulus of the CrAlN film did not change significantly. When the $\mathrm{N}_{2} / \mathrm{Ar}$ flow ratio was increased from $20 \%$ to $140 \%$, the residual stress decreased from -0.5 to -2.8 GPa. Note that residual stress value is strongly related to film hardness. To assess the suitability of coatings for tribological applications, we calculated the deformation relative to yielding $(\mathrm{H} / \mathrm{E})$ and resistance to plastic indentation $\left(\mathrm{H}^{3} / \mathrm{E}^{2}\right)$ ratios based on the nanoindentation results. Generally, the $\mathrm{H} / \mathrm{E}$ and $\mathrm{H}^{3} / \mathrm{E}^{2}$ ratios are proportional to plastic deformation resistance [29]. The average $\mathrm{H} / \mathrm{E}$ and $\mathrm{H}^{3} / \mathrm{E}^{2}$ ratios are summarized in Table 3.

Table 3. Mechanical properties of CrAlN coatings under various $\mathrm{N}_{2} / \mathrm{Ar}$ flow ratios.

\begin{tabular}{ccccccccc}
\hline $\mathbf{N}_{\mathbf{2}}$ /Ar (\%) & $\begin{array}{c}\text { Hardness } \\
\mathbf{( G P a )}\end{array}$ & $\begin{array}{c}\text { Elastic Modulus } \\
\mathbf{( G P a )}\end{array}$ & $\mathbf{H} / \mathbf{E}$ & $\mathbf{H}^{3} / \mathbf{E}^{\mathbf{2}}$ & $\mathbf{L c 1} \mathbf{( N )}$ & $\mathbf{C O F}$ & $\begin{array}{c}\text { Wear Rate } \\
\left(\mathbf{m m}^{\mathbf{3}} \cdot \mathbf{N}^{-\mathbf{1}} \cdot \mathbf{m}^{-\mathbf{1}} \mathbf{)}\right.\end{array}$ & $\begin{array}{c}\text { Residual Stress } \\
\mathbf{( G P a )}\end{array}$ \\
\hline 20 & $11.5 \pm 0.5$ & $208 \pm 7$ & 0.055 & 0.035 & 54.6 & 0.79 & $9.40 \times 10^{-6}$ & -0.5 \\
40 & $13.5 \pm 0.6$ & $265 \pm 10$ & 0.050 & 0.035 & 51.2 & 0.73 & $8.07 \times 10^{-6}$ & -0.5 \\
60 & $17.7 \pm 1.6$ & $356 \pm 34$ & 0.049 & 0.043 & 50.7 & 0.78 & $3.53 \times 10^{-6}$ & -1.5 \\
80 & $21.7 \pm 1.3$ & $383 \pm 14$ & 0.056 & 0.069 & 48.1 & 0.88 & $3.11 \times 10^{-6}$ & -1.7 \\
100 & $29.3 \pm 0.6$ & $406 \pm 15$ & 0.072 & 0.152 & 46.6 & 0.71 & $2.71 \times 10^{-6}$ & -2.3 \\
120 & $28.7 \pm 0.7$ & $397 \pm 16$ & 0.072 & 0.149 & 45.4 & 0.86 & $2.24 \times 10^{-6}$ & -2.4 \\
140 & $28.9 \pm 1.3$ & $392 \pm 20$ & 0.073 & 0.157 & 41.8 & 0.73 & $2.45 \times 10^{-6}$ & -2.8 \\
\hline
\end{tabular}

Lc1 is commonly defined as the load required to peel a film off of a given substrate, as determined by the analysis of scratch morphology. As shown in Table 3 , increasing the $\mathrm{N}_{2} /$ Ar flow ratio from $20 \%$ 
to $140 \%$ decreased the Lc1 value from 54.6 to $41.8 \mathrm{~N}$. This weak correlation between Lc1 values and $\mathrm{N}_{2} /$ Ar flow ratios can be attributed to the modulation of the interlayer structure and an increase in residual stress in the coatings following an increase in the $\mathrm{N}_{2} /$ Ar flow ratio.

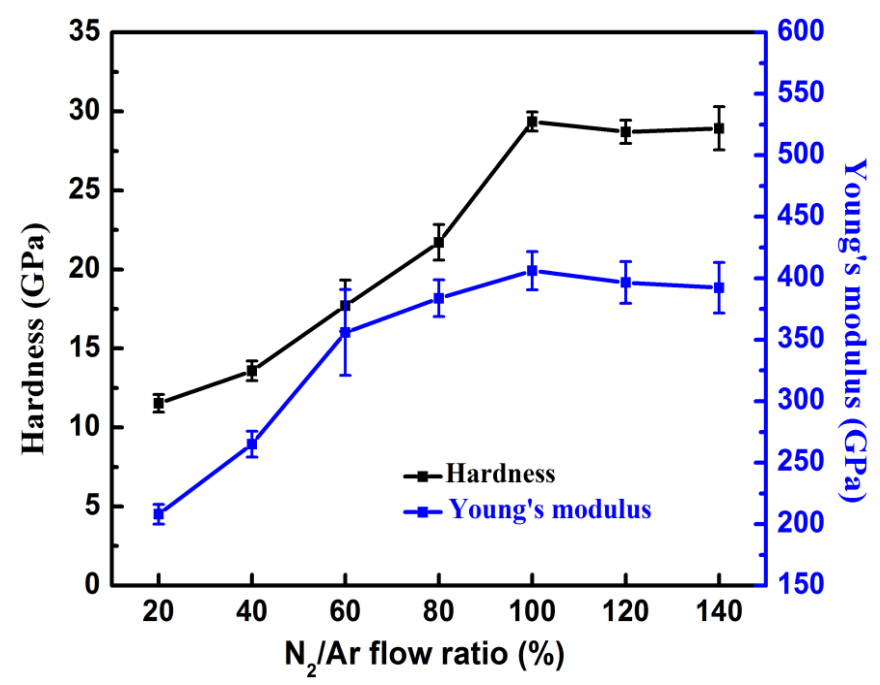

Figure 4. Hardness and Young's modulus of CrAlN layers deposited under various $\mathrm{N}_{2} /$ Ar flow ratios.

The tribological properties of the coatings depend on multiple parameters including, the microstructure, grain size, density, surface quality, and residual stress in the coatings. Table 3 lists the coefficient of friction $(\mathrm{COF})$ and average wear rates of each coating. Increasing the $\mathrm{N}_{2} / \mathrm{Ar}$ flow ratio from $20 \%$ to $140 \%$ increased the average COF from 0.7 to 0.8 . The highest wear rates $\left(9.4 \times 10^{-6} \mathrm{~mm}^{3} \cdot \mathrm{N}^{-1} \cdot \mathrm{m}^{-1}\right)$ were observed in samples formed under $\mathrm{N}_{2} /$ Ar flow ratios of less than $40 \%$, due to the lowest hardness $(11.5 \mathrm{GPa})$ and larger grain size of those films. As shown in Figure 5, the grains in the CrAlN layer formed under an $\mathrm{N}_{2} /$ Ar flow ratio of $40 \%$ were larger than those formed under an $\mathrm{N}_{2} /$ Ar flow ratio of $120 \%$. Wasekar et al. [30] reported a continuous decrease in the wear rate with a decrease in grain size. Increasing the $\mathrm{N}_{2} / \mathrm{Ar}$ flow ratio beyond $50 \%$ decreased the wear rate from $3.53 \times 10^{-6}$ to $2.45 \times 10^{-6} \mathrm{~mm}^{3} \cdot \mathrm{N}^{-1} \cdot \mathrm{m}^{-1}$, due to improvements in film hardness and tribo-chemical reactions at friction interfaces [31]. The coatings with the highest nitrogen composition presented good wear resistance as well as the highest $\mathrm{H} / \mathrm{E}$ and $\mathrm{H}^{3} / \mathrm{E}^{2}$ ratios [32]. In this section, we observed the effects of $\mathrm{N}_{2}$ /Ar flow ratio on the composition, crystal structure, and mechanical properties of CrAlN layers prepared via HiPIMS. The best mechanical properties were obtained with the $\mathrm{N}_{2} /$ Ar ratio fixed at $100 \%$. Note however, that the interpretation of these results may be best achieved using previously reported data. Wang et al. [31] reported that sharp increases in H values (from 14.0 to 22.0 GPa) and E values (from 149.9 to $198.3 \mathrm{GPa}$ ) occurred independently from the $\mathrm{N}_{2} /$ Ar flow ratio. Greczynski et al. [33] and Hurkmans et al. [34] reported similar changes in hardness with increases in the nitrogen content in the $\mathrm{CrN}_{\mathrm{x}}$ films.
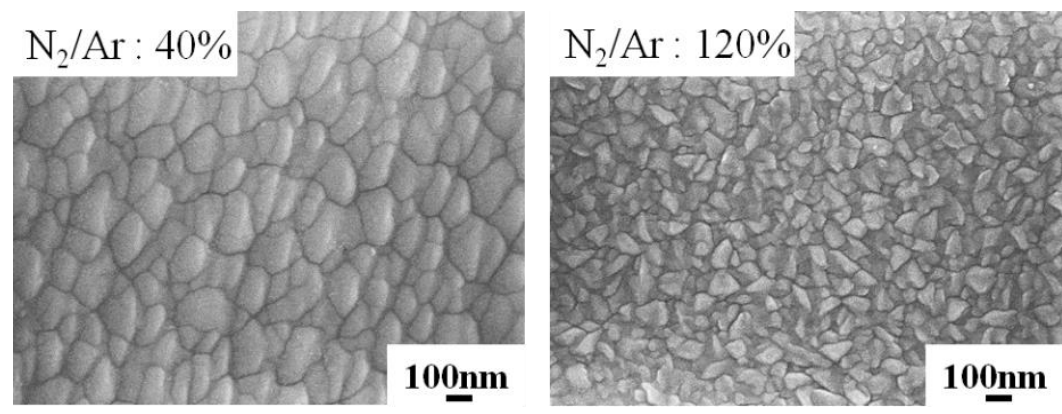

Figure 5. SEM images of CrAlN layers formed under $\mathrm{N}_{2} /$ Ar flow ratios of $40 \%$ and $120 \%$. 


\subsection{Effects of Bias Voltage on CrAlN Layers}

In this section, we examine the effects of bias voltage on the structure and mechanical properties of CrAlN layers. Table 4 lists the chemical composition of CrAlN layers formed under various bias voltages. Increasing the negative bias voltage from -30 to $-150 \mathrm{~V}$ slightly increased the $\mathrm{Al}$ content (from 23.8 to 25.6 at.\%) and the $\mathrm{Al} / \mathrm{Cr}$ ratio (from 1.09 to 1.22 ). These findings are in line with those in previous reports [18]. Previous studies have reported that increasing the bias voltage could decrease the $\mathrm{Al}$ content in the coating, due to the fact that relatively light $\mathrm{Al}$ atoms are more susceptible to re-sputtering by impinging ions than are $\mathrm{Cr}$ atoms. The discrepancy between the results in that study and the current study can be attributed to the $\mathrm{Al} / \mathrm{Cr}$ ratio of the target. Note that when using $\mathrm{AlCr}$ alloy targets with a higher $\mathrm{Al}$ content, the number of discharged $\mathrm{Al}$ ions/atoms exceeds the number of $\mathrm{Cr}$ ions/atoms [35]. In contrast, using an $\mathrm{AlCr}$ alloy target with lower $\mathrm{Al}$ content under a moderate bias voltage promotes the mobility and diffusion of the $\mathrm{Al}$ atoms on the film surface [36]. No significant differences in terms of $\mathrm{N} /(\mathrm{Al}+\mathrm{Cr})$ ratio was observed, which indicates that the nitrogen content was unaffected by bias voltage.

Table 4. Concentration of CrAlN coatings under various bias voltages.

\begin{tabular}{ccccccccc}
\hline \multirow{2}{*}{ Bias Voltage (V) } & \multicolumn{4}{c}{ Atomic Ratio (at.\%) } & \multirow{2}{*}{ Al/Cr Ratio } & Al/(Al+Cr) Ratio, $\mathbf{x}$ & N/(Al+Cr) Ratio \\
\cline { 2 - 5 } & Al & Cr & N & O & & 1.09 & 0.52 & 1.19 \\
\hline-30 & 23.8 & 21.7 & 54.1 & 0.37 & 1.08 & 0.52 & 1.14 \\
-60 & 24.2 & 22.2 & 53.1 & 0.48 & 1.22 & 0.55 & 1.12 \\
-90 & 25.8 & 21.0 & 52.9 & 0.27 & 1.18 & 0.54 & 1.10 \\
-120 & 25.6 & 21.7 & 52.4 & 0.34 & 1.22 & 0.55 & 1.12 \\
\hline-150 & 25.6 & 21.1 & 52.7 & 0.30 & & \\
\hline
\end{tabular}

Figure 6 presents XRD patterns of CrAlN layers deposited under various bias voltages. As expected, the crystalline microstructure matched the $\mathrm{NaCl}-\mathrm{B} 1$ structure (FCC) of chromium nitride. Increasing the bias voltage from -30 to $-90 \mathrm{~V}$ initially led to an increase and then a subsequent decrease in the ratio of $I(111) / I(200)$, which can be attributed to the thickness of the CrAlN coating [37]. Pelleg et al. [38] reported that the tendency toward a specific orientation can be explained by strain and surface energy. Coatings of greater thicknesses tend toward a (111) orientation, due to the effects of strain energy, whereas thinner coatings tend toward a (200) orientation. Increasing the bias voltage from -120 to $-150 \mathrm{~V}$ decreased the ratio of $I(111) / I(200)$. This is an indication that the strain energy increased rapidly to become the dominant factor (i.e., exceeding surface energy). This can be attributed to the higher intrinsic residual stress under higher bias voltages, which can have a direct effect on 200 texture [18]. As shown in Table 5, increasing the bias voltage from -30 to $-150 \mathrm{~V}$ increased the lattice parameter of the CrAlN layer from 0.4143 to $0.4195 \mathrm{~nm}$ as well as the microstrain values from $5.06 \times 10^{-3}$ to $6.78 \times 10^{-3}$. XRD data revealed left shift in the diffraction peaks indicating the presence of residual tensile stress. A further increase in the negative bias provoked a broadening of the peaks (due to presence of inhomogeneous residual stress) and a pronounced decrease in intensities [28,39].

Table 5. Structural parameter values and texture coefficients in CrAlN layers created under various bias voltages.

\begin{tabular}{cccccc}
\hline \multirow{2}{*}{ Bias Voltage (V) } & \multicolumn{2}{c}{ Lattice Parameter (nm) } & Microstrain $\varepsilon$ & \multicolumn{3}{c}{ Texture Coefficient Tc } \\
\cline { 4 - 6 } & & & $\mathbf{( 1 1 1 )}$ & $\mathbf{( 2 0 0 )}$ & $\mathbf{( 2 2 0 )}$ \\
\hline-30 & 0.4143 & $5.06 \times 10^{-3}$ & 0.51 & 1.51 & 0.97 \\
-60 & 0.4156 & $5.01 \times 10^{-3}$ & 1.01 & 0.96 & 1.03 \\
-90 & 0.4162 & $6.57 \times 10^{-3}$ & 0.92 & 1.29 & 0.78 \\
-120 & 0.4186 & $7.10 \times 10^{-3}$ & 1.07 & 1.01 & 0.92 \\
-150 & 0.4195 & $6.78 \times 10^{-3}$ & 1.04 & 1.06 & 0.88 \\
\hline
\end{tabular}




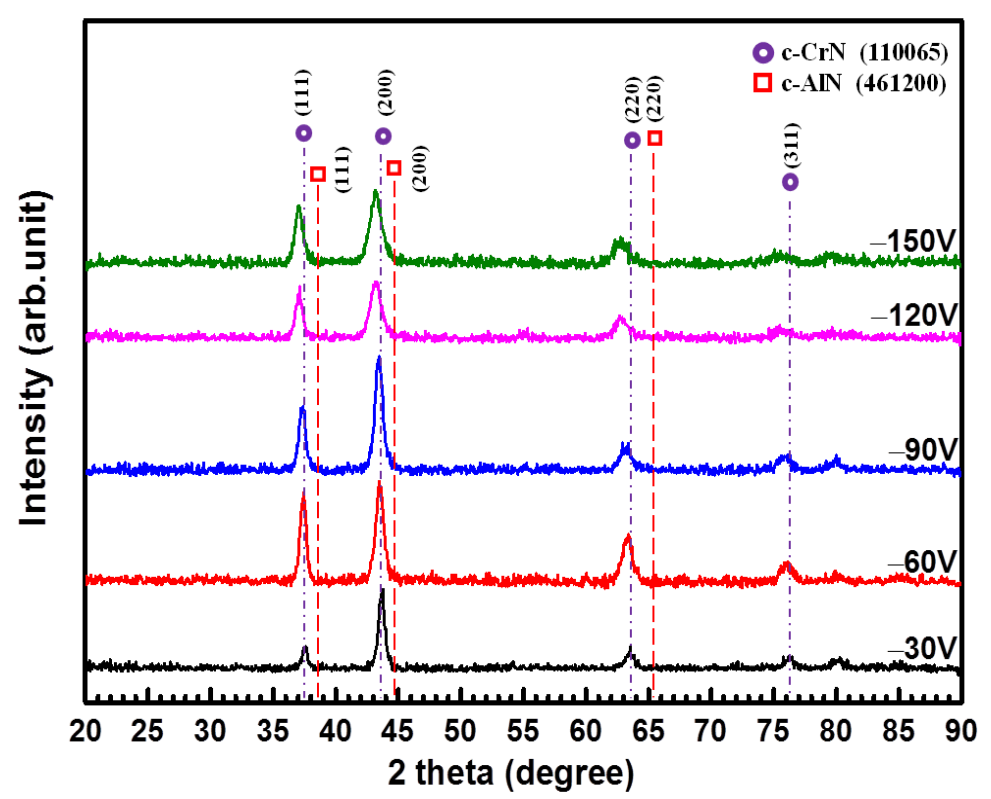

Figure 6. GIXRD profiles of CrAlN layers formed under various bias voltages.

Figure 7 presents cross-sectional SEM images of coatings deposited under various bias voltages. Increasing the bias voltage from -30 to $-90 \mathrm{~V}$ increased the deposition rate of the coating layer (from 29.2 to $30.3 \mathrm{~nm} / \mathrm{min}$ ) as well as the ultimate thickness (from 1.17 to $1.21 \mu \mathrm{m}$ ). Further increasing the bias voltage to $-150 \mathrm{~V}$ led to a decrease not only in the deposition rate of the coating layer to $28.2 \mathrm{~nm} / \mathrm{min}$ but also in the ultimate thickness to $1.13 \mu \mathrm{m}$. Under lower bias voltages, the atoms were at lower energy levels, which facilitated their deposition on the growing surface. Increasing the bias voltage to $-90 \mathrm{~V}$ increased the kinetic energy of the highly ionized $\mathrm{Cr}$ and $\mathrm{Al}$ atoms arriving at the substrate, resulting in the re-sputtering of a larger number of atoms, which suppressed the growth of the film (i.e., a lower overall rate of deposition) [40].
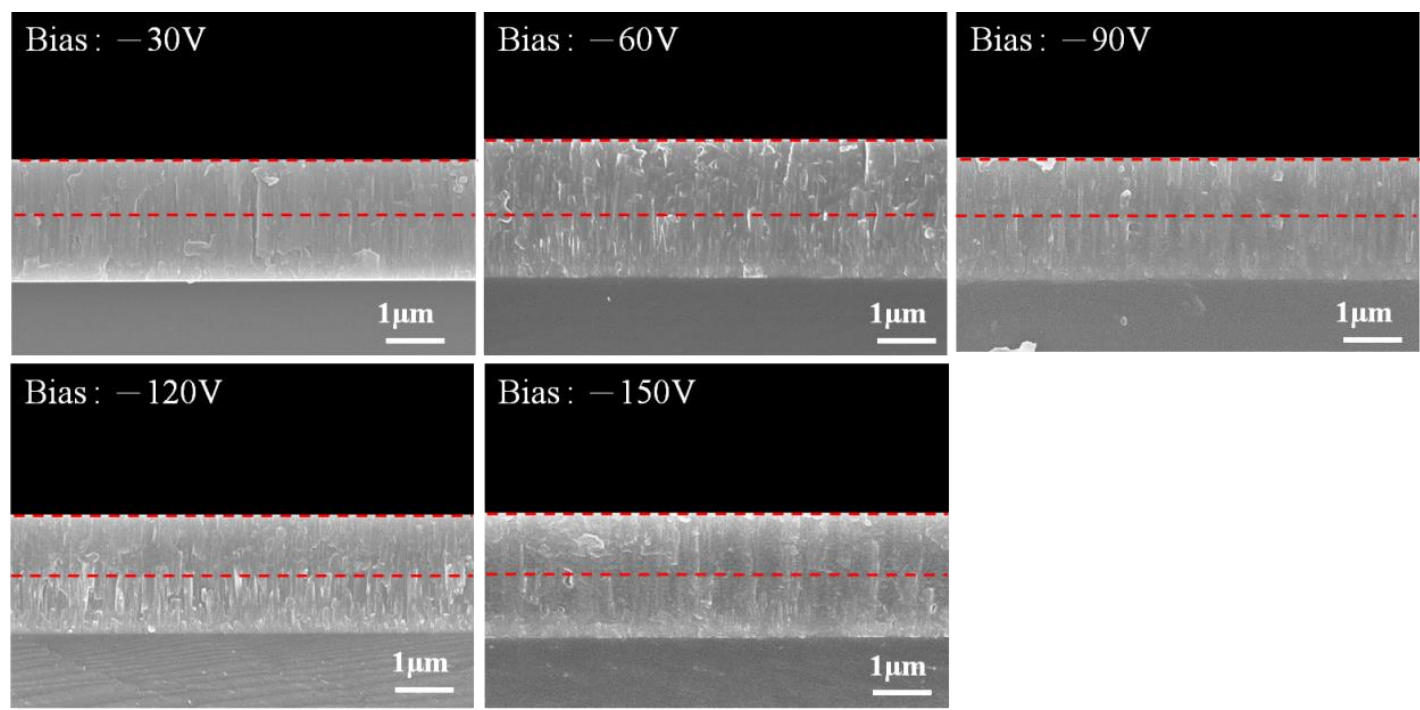

Figure 7. Cross-sectional SEM images of coatings deposited under various bias voltages.

Figure 8 presents the hardness and Young's modulus of CrAlN films obtained under various bias voltages. Increasing the bias voltage to beyond $-90 \mathrm{~V}$ led to an increase in hardness ( $\approx 35 \mathrm{GPa})$ and Young's modulus, due to the effects of grain size and residual stress in the coating. The crystallite sizes listed in Table 6 were calculated from the (111) and (200) planes. Increasing the bias voltage 
(from -30 to $-150 \mathrm{~V}$ ) decreased the crystallite sizes from 16.8 to $10.6 \mathrm{~nm}$ on the (111) plane and from 13.9 to $7.4 \mathrm{~nm}$ on the (200) plane. It has previously been reported that increasing the energy of incident ions generates a larger number of defects on the surface of growing films, which provide a larger number of nucleation sites and a corresponding increase in the number of grains (i.e., more grains of smaller size) [41]. Increasing the bias voltage was shown to increase the residual stresses in the coatings from -1.3 to $-3.1 \mathrm{GPa}$, due to high defect densities induced by ion bombardment [42].

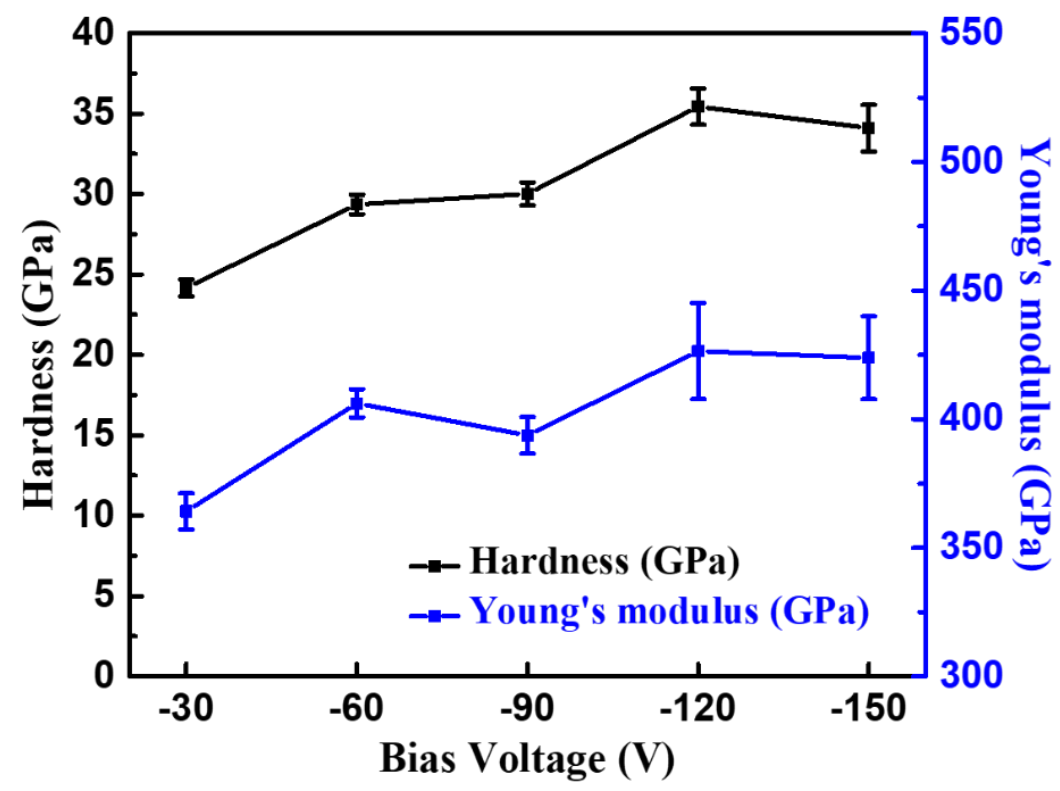

Figure 8. Hardness and Young's modulus of CrAlN layers deposited under various bias voltages.

Table 6. Mechanical properties of CrAlN coatings under various bias voltages.

\begin{tabular}{|c|c|c|c|c|c|c|c|c|c|c|}
\hline \multirow{2}{*}{$\begin{array}{c}\text { Bias } \\
\text { Voltage (V) }\end{array}$} & \multirow{2}{*}{$\begin{array}{l}\text { Hardness } \\
\text { (GPa) }\end{array}$} & \multirow{2}{*}{$\begin{array}{c}\text { Elastic } \\
\text { Modulus (GPa) }\end{array}$} & \multirow{2}{*}{$\mathrm{H} / \mathrm{E}$} & \multirow{2}{*}{$\mathrm{H}^{3} / \mathrm{E}^{2}$} & \multicolumn{2}{|c|}{$\begin{array}{l}\text { Crystallite Size } \\
\text { (nm) }\end{array}$} & \multirow{2}{*}{ Lc1 (N) } & \multirow{2}{*}{$\mathrm{COF}$} & \multirow{2}{*}{$\begin{array}{c}\text { Wear Rate } \\
\left(\mathrm{mm}^{3} \cdot \mathbf{N}^{-1} \cdot \mathrm{m}^{-1}\right)\end{array}$} & \multirow{2}{*}{$\begin{array}{l}\text { Residual Stress } \\
\qquad(\mathrm{GPa})\end{array}$} \\
\hline & & & & & (111) & $(200)$ & & & & \\
\hline-60 & $29.3 \pm 0.6$ & $406 \pm 5$ & 0.072 & 0.152 & 14.1 & 11.0 & 46.6 & 0.71 & $2.71 \times 10^{-6}$ & -2.3 \\
\hline-90 & $30.1 \pm 0.7$ & $400 \pm 7$ & 0.076 & 0.170 & 12.1 & 10.9 & 44.1 & 0.80 & $2.12 \times 10^{-6}$ & -2.5 \\
\hline-120 & $35.4 \pm 1.1$ & $426 \pm 18$ & 0.083 & 0.244 & 12.0 & 8.0 & 43.6 & 0.72 & $2.11 \times 10^{-6}$ & -2.9 \\
\hline
\end{tabular}

As shown in Table 6, increasing the bias voltage from -30 to $-150 \mathrm{~V}$ increased the Lc1 values (from 39.3 to $42.8 \mathrm{~N}$ ) as well as the residual stress. Yang et al. [43] reported that the adhesion properties of coatings are closely related to the density of the film and residual compressive stress. Low bias voltages $(-30 \mathrm{~V})$ inevitably lead to weak adhesion strength, due to the resulting low density of the coating. Note that adhesion performance can be undermined by excessive residual stress under higher bias voltages (exceeding $-60 \mathrm{~V}$ ). When the bias voltage was $-60 \mathrm{~V}$, the film exhibited a maximum Lc1 value of $46.6 \mathrm{~N}$.

Table 6 also lists the COFs and average wear rates of each coating under various bias voltages. Note that the average COF values remained constant $(\sim 0.74)$ despite variations in bias voltage. Iram et al. [44] reported that wear rates are inversely proportional to hardness values and the formation of metal oxides. In this study, increasing the bias voltage from $-30 \mathrm{~V}$ up to $-120 \mathrm{~V}$ was shown to decrease the wear rate from $3.02 \times 10^{-6}$ to $2.11 \times 10^{-6} \mathrm{~mm}^{3} \cdot \mathrm{N}^{-1} \cdot \mathrm{m}^{-1}$. Note that increasing the bias voltage to $-150 \mathrm{~V}$ led to increases in the $\mathrm{H} / \mathrm{E}$ and $\mathrm{H}^{3} / \mathrm{E}^{2}$ ratios. Increasing the bias voltage was also shown to decrease the rate of wear to $2.89 \times 10^{-6} \mathrm{~mm}^{3} \cdot \mathrm{N}^{-1} \cdot \mathrm{m}^{-1}$, under the effects of increased residual stress in the coating. 


\section{Conclusions}

Our primary objective in this study was to elucidate the effects of $\mathrm{N}_{2} / \mathrm{Ar}$ flow ratios and bias voltages on the properties of CrAlN layers deposited using HiPIMS. The conclusions are outlined in the following:

1. Increasing the $\mathrm{N}_{2} / \mathrm{Ar}$ flow ratio beyond $40 \%$ transformed the coatings from amorphous to crystalline. Increasing the $\mathrm{N}_{2} / \mathrm{Ar}$ flow ratio was also shown to decrease the deposition rate, which led to structural densification and a decrease in coating thickness, due to the fact that the sputtering rate of nitrided compounds is lower than that of metals. The hardness of the coatings ranged from 11.5 to $29.3 \mathrm{GPa}$, depending on the nitrogen concentration. This can be attributed to the stoichiometric composition and microstructure (decreased crystallite size) of the coatings.

2. Increasing the bias voltage decreased the deposition rate and the size of crystallites in the CrAlN layer, which led to a corresponding increase in hardness and residual stress. The maximum hardness achieved in this study was 35.4 GPa.

3. Increasing the $\mathrm{N}_{2} / \mathrm{Ar}$ flow ratio from $0 \%$ to $100 \%$ and the bias voltage from -30 to $-120 \mathrm{~V}$ led to a decrease in the wear rate of the coatings from $9.4 \times 10^{-6}$ to $2.11 \times 10^{-6} \mathrm{~mm}^{3} \cdot \mathrm{N}^{-1} \cdot \mathrm{m}^{-1}$. This can be attributed to increases in hardness, $\mathrm{H} / \mathrm{E}$ ratio, and $\mathrm{H}^{3} / \mathrm{E}^{2}$ ratio as well as a reduction in grain size. The adhesion of the coatings to the substrate was relatively high, withstanding critical loads (in scratch testing) of $40-50 \mathrm{~N}$.

Author Contributions: J.-F.T.: writing—original draft, writing—review \& editing. C.-Y.L.: methodology, investigation. F.-C.Y.: methodology, resources. C.-L.C.: conceptualization, supervision, writing-review \& editing. All authors have read and agreed to the published version of the manuscript.

Funding: This research was funded by the Ministry of Science and Technology, Taiwan, R.O.C, grant number [MOST 107-2622-E-131-001-CC2], [MOST 106-2218-E-131-003], and [MOST 107-2221-E-131-003].

Acknowledgments: The authors gratefully acknowledge the use of the FE-EPMA (JXA-iHP200F) apparatus at the Instrument Center of National Tsing Hua University.

Conflicts of Interest: The authors declare that they have no known competing financial interests or personal relationships that could have appeared to influence the work reported in this paper.

\section{References}

1. Dubey, P.; Arya, V.; Srivastava, S.; Singh, D.; Chandra, R. Effect of nitrogen flow rate on structural and mechanical properties of Zirconium Tungsten Nitride $(\mathrm{Zr}-\mathrm{W}-\mathrm{N})$ coatings deposited by magnetron sputtering. Surf. Coat. Technol. 2013, 236, 182-187. [CrossRef]

2. Forsén, R.; Johansson, M.; Odén, M.; Ghafoor, N. Effects of Ti alloying of AlCrN coatings on thermal stability and oxidation resistance. Thin Solid Films 2013, 534, 394-402. [CrossRef]

3. Tatemizo, N.; Imada, S.; Miura, Y.; Yamane, H.; Tanaka, K. Electronic structure of AlCrN films investigated using various photoelectron spectroscopies and ab initio calculations. J. Phys. Condens. Matter 2017, 29, 085502. [CrossRef] [PubMed]

4. Shimizu, T.; Komiya, H.; Watanabe, T.; Teranishi, Y.; Nagasaka, H.; Morikawa, K.; Yang, M. HIPIMS deposition of TiAlN films on inner wall of micro-dies and its applicability in micro-sheet metal forming. Surf. Coat. Technol. 2014, 250, 44-51. [CrossRef]

5. Paulitsch, J.; Schenkel, M.; Zufraß, T.; Mayrhofer, P.H.; Münz, W.-D. Structure and properties of high power impulse magnetron sputtering and DC magnetron sputtering $\mathrm{CrN}$ and TiN films deposited in an industrial scale unit. Thin Solid Films 2010, 518, 5558-5564. [CrossRef]

6. Bobzin, K.; Lugscheider, E.; Nickel, R.; Bagcivan, N.; Krämer, A. Wear behavior of Cr1-xAlxN PVD-coatings in dry running conditions. Wear 2007, 263, 1274-1280. [CrossRef]

7. Chang, Y.-Y.; Weng, S.-Y.; Chen, C.-H.; Fu, F.-X. High temperature oxidation and cutting performance of $\mathrm{AlCrN}, \mathrm{TiVN}$ and multilayered AlCrN/TiVN hard coatings. Surf. Coat. Technol. 2017, 332, 494-503. [CrossRef]

8. Chen, W.; Zheng, J.; Lin, Y.; Kwon, S.; Zhang, S. Comparison of AlCrN and AlCrTiSiN coatings deposited on the surface of plasma nitrocarburized high carbon steels. Appl. Surf. Sci. 2015, 332, 525-532. [CrossRef] 
9. Gilewicz, A.; Jedrzejewski, R.; Myslinski, P.; Warcholinski, B. Structure, Morphology, and Mechanical Properties of AlCrN Coatings Deposited by Cathodic Arc Evaporation. J. Mater. Eng. Perform. 2019, 28, 1522-1531. [CrossRef]

10. Tillmann, W.; Kokalj, D.; Stangier, D.; Paulus, M.; Sternemann, C.; Tolan, M. Investigation of the influence of the vanadium content on the high temperature tribo-mechanical properties of DC magnetron sputtered AlCrVN thin films. Surf. Coat. Technol. 2017, 328, 172-181. [CrossRef]

11. Endrino, J.; Fox-Rabinovich, G.; Reiter, A.; Veldhuis, S.; Galindo, R.E.; Albella, J.; Marco, J. Oxidation tuning in AlCrN coatings. Surf. Coat. Technol. 2007, 201, 4505-4511. [CrossRef]

12. Tang, J.-F.; Lin, C.-Y.; Yang, F.-C.; Tsai, Y.-J.; Chang, C.-L. Effects of nitrogen-argon flow ratio on the microstructural and mechanical properties of $\mathrm{AlCrN}$ coatings prepared using high power impulse magnetron sputtering. Surf. Coat. Technol. 2020, 386, 125484. [CrossRef]

13. Wang, Y.; Lee, J.-W.; Duh, J.-G. Mechanical strengthening in self-lubricating CrAlN/VN multilayer coatings for improved high-temperature tribological characteristics. Surf. Coat. Technol. 2016, 303, 12-17. [CrossRef]

14. Jiang, X.; Yang, F.-C.; Chen, W.-C.; Lee, J.-W.; Chang, C.-L. Effect of nitrogen-argon flow ratio on the microstructural and mechanical properties of AlSiN thin films prepared by high power impulse magnetron sputtering. Surf. Coat. Technol. 2017, 320, 138-145. [CrossRef]

15. Mahato, P.; Singh, R.; Pathak, L.; Mishra, S.K. Effect of nitrogen on mechanical, oxidation and structural behaviour of Ti-Si-B-C-N nanocomposite hard coatings deposited by DC sputtering. Surf. Interface Anal. 2016, 48, 1080-1089. [CrossRef]

16. Chen, Y.-I.; Zheng, Y.-Z.; Chang, L.-C.; Liu, Y.-H. Effect of Bias Voltage on Mechanical Properties of HiPIMS/RFMS Cosputtered Zr-Si-N Films. Materials 2019, 12, 2658. [CrossRef]

17. Biswas, B.; Purandare, Y.; Khan, I.; Hovsepian, P.E. Effect of substrate bias voltage on defect generation and their influence on corrosion and tribological properties of HIPIMS deposited CrN/NbN coatings. Surf. Coat. Technol. 2018, 344, 383-393. [CrossRef]

18. Lomello, F.; Sanchette, F.; Schuster, F.; Tabarant, M.; Billard, A. Influence of bias voltage on properties of AlCrN coatings prepared by cathodic arc deposition. Surf. Coat. Technol. 2013, 224, 77-81. [CrossRef]

19. Kim, U.-J.; Eom, S.H.; Wada, M. Thermal decomposition of native cellulose: Influence on crystallite size. Polym. Degrad. Stab. 2010, 95, 778-781. [CrossRef]

20. Warcholinski, B.; Gilewicz, A.; Lupicka, O.; Kuprin, A.; Tolmachova, G.; Ovcharenko, V.; Kolodiy, I.; Sawczak, M.; Kochmanska, A.; Kochmanski, P. Structure of CrON coatings formed in vacuum arc plasma fluxes. Surf. Coat. Technol. 2017, 309, 920-930. [CrossRef]

21. Oliver, W.C.; Pharr, G.M. An improved technique for determining hardness and elastic modulus using load and displacement sensing indentation experiments. J. Mater. Res. 1992, 7, 1564-1583. [CrossRef]

22. Chen, S.-F.; Kuo, Y.-C.; Wang, C.-J.; Huang, S.-H.; Lee, J.-W.; Chan, Y.-C.; Chen, H.-W.; Duh, J.-G.; Hsieh, T.-E. The effect of $\mathrm{Cr} / \mathrm{Zr}$ chemical composition ratios on the mechanical properties of $\mathrm{CrN} / \mathrm{ZrN}$ multilayered coatings deposited by cathodic arc deposition system. Surf. Coat. Technol. 2013, 231, 247-252. [CrossRef]

23. Hiratsuka, M.; Azuma, A.; Nakamori, H.; Kogo, Y.; Yukimura, K. Extraordinary deposition rate of diamond-like carbon film using HIPIMS technology. Surf. Coat. Technol. 2013, 229, 46-49. [CrossRef]

24. Liu, H.; Tang, J.-F.; Wang, X.; Li, W.; Chang, C.-L. Effects of nitrogen-argon flow ratio on the microstructural and mechanical properties of TiAlSiN/CrN multilayer coatings prepared using high power impulse magnetron sputtering. J. Vac. Sci. Technol. A 2019, 37, 051501. [CrossRef]

25. Li, Q.; Cheng, X.; Gong, D.; Ye, W. Effect of N2 flow rate on structural and infrared properties of multi-layer $\mathrm{AlCrN} / \mathrm{Cr} / \mathrm{AlCrN}$ coatings deposited by cathodic arc ion plating for low emissivity applications. Thin Solid Films 2019, 675, 74-85. [CrossRef]

26. Ferreira, F.; Oliveira, J.; Cavaleiro, A. CrN thin films deposited by HiPIMS in DOMS mode. Surf. Coat. Technol. 2016, 291, 365-375. [CrossRef]

27. Han, Z.; Tian, J.; Lai, Q.; Yu, X.; Li, G. Effect of N2 partial pressure on the microstructure and mechanical properties of magnetron sputtered CrNx films. Surf. Coat. Technol. 2003, 162, 189-193. [CrossRef]

28. Forniés, E.; Galindo, R.E.; Sánchez, O.; Albella, J. Growth of CrNx films by DC reactive magnetron sputtering at constant N2/Ar gas flow. Surf. Coat. Technol. 2006, 200, 6047-6053. [CrossRef]

29. Warcholinski, B.; Gilewicz, A.; Kuprin, A.; Tolmachova, G.; Ovcharenko, V.; Kuznetsova, T.; Zubar, T.; Khudoley, A.; Chizhik, S. Mechanical properties of Cr-ON coatings deposited by cathodic arc evaporation. Vacuum 2018, 156, 97-107. [CrossRef] 
30. Wasekar, N.P.; Haridoss, P.; Seshadri, S.; Sundararajan, G. Sliding wear behavior of nanocrystalline nickel coatings: Influence of grain size. Wear 2012, 296, 536-546. [CrossRef]

31. Li, B.-S.; Wang, T.-G.; Ding, J.; Cai, Y.; Shi, J.; Zhang, X. Influence of N2/Ar flow ratio on microstructure and properties of the $\mathrm{AlCrSiN}$ coatings deposited by high-power impulse magnetron sputtering. Coatings 2018, 8, 3. [CrossRef]

32. Warcholinski, B.; Gilewicz, A.; Kuznetsova, T.; Zubar, T.; Chizhik, S.; Abetkovskaia, S.; Lapitskaya, V. Mechanical properties of Mo (C) N coatings deposited using cathodic arc evaporation. Surf. Coat. Technol. 2017, 319, 117-128. [CrossRef]

33. Greczynski, G.; Jensen, J.; Hultman, L. Films Prepared by DC Magnetron Sputtering and High-Power Pulsed Magnetron Sputtering: A Comparative Study. IEEE Trans. Plasma Sci. 2010, 38, 3046-3056. [CrossRef]

34. Hurkmans, T.; Lewis, D.; Brooks, J.; Münz, W.-D. Chromium nitride coatings grown by unbalanced magnetron (UBM) and combined arc/unbalanced magnetron (ABS'M) deposition techniques. Surf. Coat. Technol. 1996, 86, 192-199. [CrossRef]

35. Sabitzer, C.; Paulitsch, J.; Kolozsvári, S.; Rachbauer, R.; Mayrhofer, P. Influence of bias potential and layer arrangement on structure and mechanical properties of arc evaporated Al-Cr-N coatings. Vacuum 2014, 106, 49-52. [CrossRef]

36. Lv, Y.; Ji, L.; Liu, X.; Li, H.; Zhou, H.; Chen, J. Influence of substrate bias voltage on structure and properties of the CrAlN films deposited by unbalanced magnetron sputtering. Appl. Surf. Sci. 2012, 258, 3864-3870. [CrossRef]

37. Nouveau, C.; Djouadi, M.; Banakh, O.; Sanjinés, R.; Lévy, F. Stress and structure profiles for chromium nitride coatings deposited by rf magnetron sputtering. Thin Solid Films 2001, 398, 490-495. [CrossRef]

38. Pelleg, J.; Zevin, L.; Lungo, S.; Croitoru, N. Reactive-sputter-deposited TiN films on glass substrates. Thin Solid Films 1991, 197, 117-128. [CrossRef]

39. Warcholinski, B.; Kuznetsova, T.; Gilewicz, A.; Zubar, T.; Lapitskaya, V.; Chizhik, S.; Komarov, A.; Komarova, V.; Kuprin, A.; Ovcharenko, V.; et al. Structural and mechanical properties of Zr-Si-N coatings deposited by arc evaporation at different substrate bias voltages. J. Mater. Eng. Perform. 2018, 27, 3940-3950. [CrossRef]

40. Rong, S.; He, J.; Wang, H.; Tian, C.; Guo, L.; Fu, D. Effects of bias voltage on the structure and mechanical properties of thick CrN coatings deposited by mid-frequency magnetron sputtering. Plasma Sci. Technol. 2009, 11, 38. [CrossRef]

41. Lee, J.-W.; Tien, S.-K.; Kuo, Y.-C. The effects of pulse frequency and substrate bias to the mechanical properties of CrN coatings deposited by pulsed DC magnetron sputtering. Thin Solid Films 2006, 494, 161-167. [CrossRef]

42. Kong, Q.; Ji, L.; Li, H.; Liu, X.; Wang, Y.; Chen, J.; Zhou, H. Influence of substrate bias voltage on the microstructure and residual stress of $\mathrm{CrN}$ films deposited by medium frequency magnetron sputtering. Mater. Sci. Eng. B 2011, 176, 850-854. [CrossRef]

43. Chen, X.; Xi, Y.; Meng, J.; Pang, X.; Yang, H. Effects of substrate bias voltage on mechanical properties and tribological behaviors of RF sputtered multilayer TiN/CrAlN films. J. Alloys Compd. 2016, 665, 210-217. [CrossRef]

44. Iram, S.; Cai, F.; Wang, J.; Zhang, J.; Liang, J.; Ahmad, F.; Zhang, S. Effect of Addition of Mo or V on the Structure and Cutting Performance of AlCrN-Based Coatings. Coatings 2020, 10, 298. [CrossRef]

(C) 2020 by the authors. Licensee MDPI, Basel, Switzerland. This article is an open access article distributed under the terms and conditions of the Creative Commons Attribution (CC BY) license (http://creativecommons.org/licenses/by/4.0/). 